\title{
Verzeichnis der Dokumente und Statistiken
}

I. Gesetze, Verordnungen, Anordnungen $\ldots \ldots \ldots \ldots \ldots \ldots \ldots \ldots \ldots \ldots \ldots$

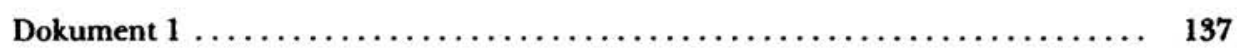

Verordnung über die Rūckgabe Deutscher Personalausweise bei Übersiedlung nach Westdeutschland oder Westberlin, 25.1.1951

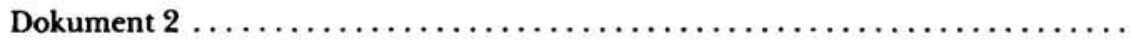

Verordnung über Maßnahmen an der Demarkationslinie zwischen der

Deutschen Demokratischen Republik und den westlichen Besatzungszonen

Deutschlands, 26.5. 1952

Dokument 3

Verordnung zur Sicherung von Vermögenswerten, 17. 7.1952

Dokument 4

Anordnung über die Einziehung der Deutschen Personalausweise

bei Ausgabe von Interzonenpässen, 25. 2. 1953

Dokument 5

Verordnung über die in das Gebiet der Deutschen Demokratischen Republik und den demokratischen Sektor von Groß-Berlin zurückkehrenden Personen, 11. 6.1953

Dokument 6

Verordnung ūber die Ausgabe von Personalausweisen der Deutschen Demokratischen Republik, 29. 10.1953

Dokument 7

Anordnung über die finanzielle Hilfe für Personen, die ihren Wohnsitz aus Westdeutschland und Westberlin in das Gebiet der Deutschen Demokratischen Republik oder des demokratischen Sektors von Groß-Berlin verlegen, 29. 4. 1954

Gesetz zur Änderung des Paßgesetzes der Deutschen Demokratischen Republik, 11. 12.1957 
Dokument 9

HVDVP, Hauptabteilung PK (Klein), Bericht über den Tod des Schneidermeisters und SED-Mitglieds Tippach am 7.4.1951 in Groß Burschla (Thüringen) und über die politische Lage im Grenzgebiet, 16.4. 1951

Dokument 10

Öffentlicher Aushang der Polizeiverordnung über die Einführung einer besonderen Ordnung an der Demarkationslinie, Ministerium für Staatssicherheit, Zaisser, o.D. (Inkrafttreten: 27.5. 1952)

Dokument 11

HVDVP, HA S-, Zwischenbericht der Überprüfung der Dienstdurchführung an der Sektorengrenze durch die Bereitschaften des PdVP Berlin, 22. 4. 1959

III. Berichte uber die Republikflucht.

Dokument 12

Statistische Erfassung der aus der Ostzone nach dem Westen geflüchteten Personen, 9.3. 1948

Dokument 13

Bericht über die Republikflucht im Bezirk Rostock von Ende 1952, o.D., o.V.

Dokument 14

BDVP Erfurt, Leiter der Abt. K, VP-Inspekteur Zahmel, Bericht über

DDR-flūchtige Betriebsangehörige vom VEB Rheinmetall Sōmmerda und Analyse über diesen Personenkreis, 21. 10. 1953

Dokument 15

Untersuchung über die Gründe der Republikflucht und der Rückkehr nach sozialen Gruppen: Intelligenz, Bauern, Jugendliche etc., o.T., o.D [handschriftlich 1955]

Dokument 16

Protokoll Nr. 29/56 der Sitzung des Politbüros des Zentralkomitees vom 19. 6. 1956, Anlage Nr. 4: Bericht der Kommission zu Fragen der Republikflucht, 25.5. 1956 
Dokument 17 .

Schreiben des Chefinspekteurs der Volkspolizei, Seifert, an ZK der SED,

Genosse Sorgenicht: Auszüge aus einem Bericht über Republikfluchten

in der Bezirksbehörde der DVP Gera, 6. 7. 1956

Dokument 18

Staatssekretãr im MdI, Generalmajor der VP Grünstein an Generalmajor

der VP Dombrowsky, Analyse über die Republikfluchten der Lehrer von den

Grund-, Mittel- und Oberschulen sowie Sonderschulen, 2. 12. 1958 (Auszug)

Dokument 19

HVDVP, HA PM, Fischer, an ZK der SED, Abt. Sicherheitsfragen,

Republikflucht von Ärzten im Jahr 1957, 25. 1.1958

Dokument 20

Abteilung Innere Angelegenheiten, Sektor I, Probleme, die in Zusammenhang mit der Republikflucht von Jugendlichen getreten sind, 22. 10. 1960

Dokument 21

Ministerium für Staatssicherheit an Ulbricht, Neumann, Honecker,

Grüneberg und Röhlig, Information Nr. 313/60: Bericht über die Entwicklung der Republikflucht in der Zeit vom 1.4.-20.4. 1960, 23. 4. 1960

Dokument 21 a

Nachtrag (Abwerbebrief) zur Information Nr. 313/60 vom 23.4. 1960

IV. Maßnahmen gegen dle Republikfiucht

Dokument 22

Protokoll Nr. 222 der Sitzung des Sekretariats des ZK am 22. 12. 1952,

Anlage Nr. 6: Richtlinien ūber Maßnahmen gegen die Republikflucht und zur Werbung von Fachkrāften in Westdeutschland

Dokument 23

Schreiben des 1. und 2. Sekretārs der SED-Betriebsparteiorganisation des

VEB-Edelstahlwerks Döhlen an die HVDVP, Abt. PM, 22. 7. 1954

Dokument 23 a

Antwortschreiben des VP-Inspekteurs Fischer, Leiter der Abt. PM 1, an die

Betriebsparteiorganisation des VEB-Edelstahlwerkes Dōhlen, 5. 8. 1954 
Dokument 24

Der Minister für Staatssicherheit, Generaloberst Mielke, Anweisung Nr. 1/60, Politisch-operative Maßnahmen zur Einengung der Republikfluchten, 4. 5. 1960

Dokument 24 a .

Der Minister für Staatssicherheit, Generaloberst Mielke, betr. politisch-operative Maßnahmen und Erfahrungen zur Einschränkung und Verhinderung von Republikfluchten in Ausführung der Anweisung Nr. 1/60 vom 4. 5. 1960, 7. 7. 1960

Dokument 24 b

Entwurf: Maßnahmen und Vorschläge zur Bekāmpfung der Republikflucht (Ergänzung zur Anweisung Nr. 1/60 v. 4.5. 1960), o.V., o.D. (Auszug)

Dokument 25

Wort der Synode der Evangelischen Kirche der Union vom November 1960 an die Gemeinden, o.V., o.D.

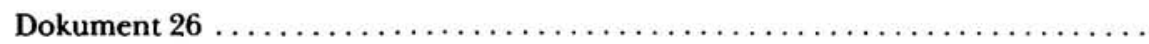

Der Generalsuperintendent der Neumark und der Niederlausitz, D. Gūnther Jacob, an den Arzt Dr. R[...], 13. 11. 1960

Dokument 27

HVDVP, Leiter der HA PM, Oberst der VP, Fischer, an VK, Gen. Anstett; AZKW, Müncheberg; HA K, Gen. Rothe; HA Innere Angelegenheiten, Gen. Bergmann; HA PM, Behandlung von Rückkehrern, die mit Kraftfahrzeugen einreisen wollen, 13. 12. 1957

Dokument 28

Gemeinsamer offener Brief der Betriebsgewerkschaftsleitung, der Betriebsparteiorganisation und der Betriebsleitung an alle Belegschaftsangehörigen des Kreiskrankenhauses/Poliklinik Altenburg, Sãuglingsheilanstalt, 13.8. 1957

V. Abschiedsbriefe und andere private Briefe

Dokument 29

Abschiedsbrief des Arztes Dr. R.H. an seinen Vorgesetzten, 12. 5. 1959

Dokument 30

Abschiedsbrief des Arztes G.St. an den Oberarzt Dr. K., 29. 5. 1959 
Dokument 31

Abschiedsbrief des CDU-Abgeordneten im Sachsen-Anhaltinischen Landtag und Prãsidialrat der CDU, Fritz-Georg Jordan, an den Vorsitzenden der CDU Sachsen-Anhalt, Wujciak, 16.8.1950

Dokument 31 a 236

Abschiedsbrief des CDU-Abgeordneten im Sachsen-Anhaltinischen Landtag und Prāsidialrat der CDU, Fritz-Georg Jordan, an seine Parteifreunde, 19. 8. 1950

Dokument 32

Abschiedsbrief von H. K[...] an das Entwurfsbüro für Hochbau des Rates des Bezirkes Schwerin, Kaderabeilung, 20. 1. 1958

Dokument 33 . 238

Abschiedsbrief des Kinderarztes Dr. Dieter P[...], tātig als Oberarzt in der Kinderklinik im Krankenhaus Dresdner Str., Karl-Marx-Stadt, 19. 10. 1960

Dokument 34

Brief von M.G. aus Hücheln an seinen ehemaligen Kollegen P.V., 10. 10. 1957

Dokument 35

Anonymer Brief an das Politbüro des ZK der SED mit Vorschlägen zu Maßnahmen gegen die Republikflucht, 27.11.1957

VI. West-Ost-Wanderung.

Dokument 36

„Die Fluchtbewegung aus Westdeutschland und Westberlin in die Deutsche Demokratische Republik“, o.V., 13.8.1960

Dokument 37

Protokoll über die Rücksprache mit dem zurückgekehrten desertierten und in den Westen geflūchteten VP-Wachtmeister Horst Sch [...] und dessen Ehefrau, 8.1. 1957

VII. Zeitungs- und Zeitschriftenartikel

Dokument 38

Satirischer Artikel von Erich Brehm, Ein "politischer" Flüchtling, September 1952 
Dokument 39

Artikel über eine zurūckgekehrte Flūchtlingsfrau, „Eine Frau kehrte zurūck“,

14. 4.1961

Dokument 40

Erlebnisbericht eines desertierten und geflūchteten Volkspolizisten,

"Wie mich RIAS-Agenten nach West-Berlin lockten ", 29. 1. 1954

Dokument 41

Artikel über Republikflūchtige, ${ }_{n}$ Hunger und Elend - das westliche ,Paradies

Republikflüchtige bitten die Regierung der DDR um Wiederaufnahme“ ${ }^{\star}$, 7. 2. 1953

Dokument 42 . .

Artikel über zurückgekehrte Flūchtlinge, „Warum sie zurūckkamen“, 22. 7. 1953

VII. Statistiken.

Tabelle 1

Monatliche Abwanderung nach Westdeutschland und West-Berlin

Tabelle 2

Monatliche Zuwanderung von Westdeutschland und West-Berlin

Tabelle 3

Jährliche Abwanderung nach Westdeutschland und West-Berlin nach Berufen

Grafik 1

Monatliche $\mathrm{Zu}$ - und Abwanderung von / nach Westdeutschland und West-Berlin

Grafik 2

Jāhrliche Abwanderung nach Westdeutschland und West-Berlin 